\title{
Chloroquine and Hydroxychloroquine in Treatment of Coronavirus Disease-19
}

\author{
Lidija Poposka*, Irena Mitevska \\ University Clinic for Cardiology, Faculty of Medicine, University Ss Cyril and Methodius, Skopje, Republic of Macedonia
}

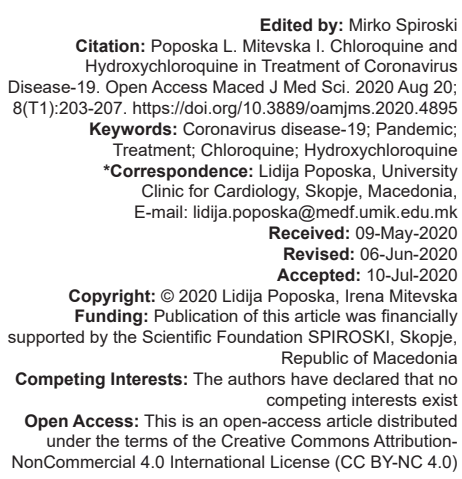

Edited by: Mirko Spirosk Edited by: Mirko Spirosk
Citation: Poposka L. Mitevska I. Chloroquine and Disease-19. Open Access Maced J Med Sci. 2020 Aug 20 8(T1):203-207. https://doi.org/10.3889/oamims. 2020.4895 Keywords: Coronavirus disease-19; Pandemic Treatment; Chloroquine; Hydroxychloroquine *Correspondence: Lidija Poposka, University Clinic for Cardiology, Skopje, Macedonia, E-mail: lidija.poposka@medf.umik.edu.mk Received: 09-May-2020 Revised: 06-Jun-2020 Copyright: $\odot 2020$ Lidija Poposka, Irena Mitevska Funding: Publication of Pop article was financially supported by the Scientific Foundation SPIROSKI, Skopje,
Republic of Macedonia Republic of Macedoni
Competing Interests: The authors have declared that no Open Access: This is an open-access article distributed under the terms of the Creative Commons Attribution-
NonCommercial 4.0 International License (CC BY-NC 4.0)

\begin{abstract}
At present, we are facing coronavirus disease (COVID)-19 pandemic caused by the severe acute respiratory syndrome coronavirus- 2 with several treatment choices and reports of different treatment outcomes. Chloroquine and hydroxychloroquine use for the management of severely ill patients started as a quite enthusiastic treatment option, following several small clinical trials, case series reports, public authorities, and media affirmation. However, the evidence we have so far is conflicting and some national societies and professional institutions implicate that we should wait for definite treatment recommendations until there are solid data for or against the use of these drugs. Until we have more powerful evidence in our hands, we should be aware of safety issues of the old drugs for the new application in the emergency state we are facing today with the COVID-19 pandemic. We performed a concise review of strengths, limitations, and awareness for chloroquine and hydroxychloroquine use for COVID-19 infection treatment based on the evidence the science has today.
\end{abstract}

\section{Introduction}

Chloroquine and its analog hydroxychloroquine, drugs that had been used to treat malaria and systemic lupus erythematosus, rheumatoid arthritis, are recently promoted as a potential treatment for the coronavirus disease (COVID)-19. Initial results on the efficacy of chloroquine in severe acute respiratory syndrome caused by coronavirus-2 (SARS-CoV-2) are derived from in vitro studies [1]. The first results from patients with SARS-CoV-2-related pneumonia and chloroquine efficacy come form China [2].

Hydroxychloroquine as an analog of chloroquine with less gastric intolerance and less concerns for drug interactions was found in vitro to be more potent than chloroquine in inhibiting SARS-CoV-2 [3].

Food and drug administration (FDA) allowed the use of these drugs since April 2020 to certain hospitalized patients where health-care providers and patients are provided with information about the risks of these drugs [4]. However, after first enthusiasm, FDA has expressed caution against the use of these drugs for COVID-19 outside of the hospital settings or a clinical trial due to the risk of heart rhythm problems and close supervision was strongly recommended. Clinical trials are planned and some have been underway to determine efficacy and safety of these drugs in the treatment of COVID-19 infection. At the beginning of April 2020, World Health Organization has started a multi-arm, multi-country clinical trial for potential coronavirus therapies based on evidence from laboratory, animal, and clinical studies, among which chloroquine and hydroxychloroquine treatment is included in the study.

Rational to use chloroquine analog lays in the fact that this drug is found to be effective against a variety of viral infections by inhibiting acidification of endosomes during the replication of the virus and infection and by their immunomodulatory effects [5]. Therapeutic agents such as chloroquine analogs, acting with the prevention of activation of macrophages, and inhibition of the secretion of tumor necrosis factor $\alpha$ and interleukin 6 from various cells would express benefits in the treatment of viral infections [6], [7].

\section{Materials and Methods}

A literature review was performed using PubMed to identify relevant articles published through April 15, 2020. Used search terms were coronavirus, COVID-19, SARS-CoV-2, and chloroquine, hydroxychloroquine. This search resulted in 59 total articles. Additional 
relevant articles were identified from the review of citations referenced. Case reports were also included.

The search terms COVID-19 or coronavirus or SARS-COV-2 and chloroquine or hydroxychloroquine on clinicaltrials.gov resulted in 14 active trials as of April 15, 2020. Ten of the trials are already recruiting patients, four still not recruiting patients. Seven of them are testing chloroquine or hydroxychloroquine alone, or controlled with placebo, three are testing low versus high dose hydroxychloroquine, and four are testing hydroxychloroquine versus hydroxychloroquine and azithromycin.

\section{Discussion}

Chloroquine, as an antimalarial drug, present at the pharmaceutical market more than 70 years has been tested regarding its safety profile multiple times. For many decades, people visiting malaria-endemic geographic areas received chloroquine prophylaxis and continued it for months after return in their homelands. In addition, some local residents in African countries took chloroquine continuously without any remarkable side effects. Hydroxychloroquine, on the other hand, has been used for a long time at much higher doses (up to $600 \mathrm{mg} /$ day) for the treatment of certain autoimmune diseases. Regarding the longevity of clinical use and number of treated patients, nowadays, we can easily talk about good established safety profile of these drugs.

However, in the circumstances of acute viral infection with sometimes severe clinical presentation, attacking multiple systems, producing electrolyte, and metabolic changes, treatment with chloroquine/ hydroxychloroquine may lead to dangerous adverse effects.

\section{Results from clinical studies}

After the initial modest positive results, the problem had appeared when many hospitals have simply been giving these drugs to all infected patients, without proven efficacy, concerning that treatment is relatively safe. The reports in literature from France, Brazil, China, US are conflicting; some do not include control groups, many have a small number of participants and have no power to draw conclusions, and conclusions are conflicting.

Published studies are summarized in Table 1.

The earliest published studies from China and France have been widely criticized because there was no control group to compare treated versus untreated patients. Some researchers even called this report anecdotal. In the open-label, non-randomized study, Gautret et al. reported $100 \%$ viral clearance in nasopharyngeal swabs in six patients after 5-6 days of treatment with hydroxychloroquine and azithromycin [8]. Such a rapid and full viral clearance was quite unexpected to other authors. A study from China in patients with COVID-19 infection did not found any difference in virologic clearance with, or without treatment with hydroxychloroquine, and even more no difference in the clinical course of the disease [9].

Asmall double-blind, randomized study in Brazil (81 patients) was discontinued early for safety reasons after patients on a higher dose of chloroquine showed increased mortality due to QTc interval prolongation on recorded standard 12 lead electrocardiogram and associated proarrhythmias [10].

Despite the again small size of the previous study, infectologists and drug safety experts express their opinion that the study provided further evidence that chloroquine and hydroxychloroquine can pose significant harm to some patients, specifically the risk of a fatal arrhythmia. Patients in Brazilian study were also given azithromycin, which also prolongs QTc interval. It seems that we need more data at every level.

Barbosa et al. decided to publish preliminary results, although their dataset is growly rapidly because of concerning safety signals [11]. They showed that hydroxychloroquine did not appear to have a beneficial effect on meaningful clinical outcome measures of mortality, lymphopenia reconstitution,

Table 1: Published studies about treatment with chloroquine or hydroxychloroquine for COVID-19 disease

\begin{tabular}{|c|c|c|c|c|}
\hline Title & Drug & Type & Number of participants & Results \\
\hline $\begin{array}{l}\text { Hydroxychloroquine and azithromycin as a } \\
\text { treatment of COVID-19: results of an open-label } \\
\text { non-randomized clinical trial [8] }\end{array}$ & $\begin{array}{l}\text { Hydroxychloroquine } 200 \mathrm{mg} \times 3 \text { and } \\
\text { azithromycin, versus placebo }\end{array}$ & $\begin{array}{l}\text { Open-label } \\
\text { non-randomized }\end{array}$ & 36 & $\begin{array}{l}\text { Improved virologic clearance in treatment } \\
\text { arm addition of azithromycin resulted in } \\
\text { superior viral clearance }\end{array}$ \\
\hline $\begin{array}{l}\text { A pilot study of hydroxychloroquine in treatment } \\
\text { of patients with common COVID-19 [9] }\end{array}$ & $\begin{array}{l}\text { Hydroxychloroquine, } 400 \mathrm{mg} \text {, daily for } 5 \\
\text { days plus standard of care or standard care } \\
\text { alone in a } 1: 1 \text { fashion; }\end{array}$ & Open-label & 30 & $\begin{array}{l}\text { No } \\
\text { difference in virologic outcomes }\end{array}$ \\
\hline $\begin{array}{l}\text { Chloroquine diphosphate for the treatment of } \\
\text { severe acute respiratory syndrome secondary to } \\
\text { SARS-CoV2 (CloroCOVID19) NCT04323527 [10] }\end{array}$ & $\begin{array}{l}\text { Low dose chloroquine diphosphate }(450 \\
\mathrm{mg}), 5 \text { days versus high dose }(600 \mathrm{mg}) 10 \\
\text { days }\end{array}$ & $\begin{array}{l}\text { Double-blind, } \\
\text { randomized } \\
\text { adaptive clinical trial }\end{array}$ & $\begin{array}{l}440 \text { ongoing data } \\
\text { published for } 81 \text { pts. }\end{array}$ & $\begin{array}{l}\text { Higher dose of chloroquine for } 10 \text { days was } \\
\text { associated with more toxic effect and lethality, } \\
\text { particularly affecting QTc prolongation }\end{array}$ \\
\hline $\begin{array}{l}\text { Clinical outcomes of hydroxychloroquine in } \\
\text { hospitalized patients with COVID-19: A quasi- } \\
\text { Randomized comparative study [11] }\end{array}$ & $\begin{array}{l}\text { Hydroxychloroquine and supportive care } \\
\text { versus supportive care alone initial loading } \\
\text { dose of } 400 \mathrm{mg} \text { b.i.d } 1-2 \text { days and } 3-4 \\
\text { subsequent days } 200 \mathrm{mg}-400 \mathrm{mg} \text { o.d. }\end{array}$ & Quasi-randomized & 63 & $\begin{array}{l}\text { Hydroxychloroquine was associated } \\
\text { with an increased need for escalation } \\
\text { of respiratory support. No benefits } \\
\text { of hydroxychloroquine on mortality, } \\
\text { lymphopenia, or neutrophil-to-lymphocyte } \\
\text { ratio improvement }\end{array}$ \\
\hline $\begin{array}{l}\text { Efficacy of hydroxychloroquine in patients with } \\
\text { COVID-19: results of a randomized clinical trial } \\
\text { ChiCTR2000029559 [12] }\end{array}$ & $\begin{array}{l}\text { Hydroxychloroquine } 400 \mathrm{mg} / \mathrm{d}(200 \mathrm{mg} / \\
\text { bid) between days } 1 \text { and } 5 \text { versus standard } \\
\text { treatment only. }\end{array}$ & $\begin{array}{l}\text { Randomized } \\
\text { parallel-group trial }\end{array}$ & 62 & $\begin{array}{l}\text { Hydroxychloroquine use shortened time to } \\
\text { clinical recovery }\end{array}$ \\
\hline
\end{tabular}


neutrophil-to-lymphocyte ratio, or risk for intubation. Patients in hydroxychloroquine arm appeared to have a worse clinical outcome in terms of need of respiratory support [11]. These results were in contrast to previously published results from Chen et al., showing shortened time to clinical recovery in hydroxychloroquine group in comparison with the control group (body temperature recovery time and cough remission time) [12].

The true answer to whether chloroquine or hydroxychloroquine has a beneficial effect for COVID-19 patients can only be obtained with a prospective randomized clinical study (Table 1).

\section{Recommendations}

According to the tendency of doctors and hospitals to give chloroquine or hydroxychloroquine, especially to severe ill patients, some associations, expert groups have published recommendations, and some refrain from making recommendations until the results of relevant clinical studies come out (Table 2).

Table 2: Available guidance about the treatment with chloroquine/hydroxychloroquine up to April 2020

Multicenter collaboration group of
Department of Science and Technology
of Guangdong Province and Health
Commission of Guangdong Province
for chloroquine in the treatment of
novel coronavirus pneumonia. Expert
consensus on chloroquine phosphate
for the treatment of novel coronavirus
pneumonia.
Zhonghua Jie He He Hu Xi Za Zhi. 20
February 2020; 43 (0): E019.
Diagnosis and treatment protocol for
novel coronavirus pneumonia (Trial
Version 7)
(Released by National Health Commission
and State Administration of Traditional
Chinese Medicine on March 3, 2020)
Handbook for the care of people with
disease-COVI 19
Edition 2.0, March 13, 2020
SIMIT
Italian Society of Infectious and Tropical
Diseases SECTION Regione Lombardia

ESC guidance for the diagnosis and management of $\mathrm{CV}$ disease during the COVID-19 pandemic

escardio.org/Education

COVID-19-and-Cardiology/

ESC-COVID-19-Guidance

Clinical management of severe acute

respiratory infection when COVID-19 is

suspected

Interim guidance

March 13, 2020,।

World Health Organization

COVID-19

Interim Clinical Guidance for Management

of Patients with confirmed COVID-19

CDC Center for Disease Control and

Prevention

COVID-19: Coronavirus disease 2019.

Chloroquine phosphate $(500 \mathrm{mg}$ bid for 7 days for adults aged 18-65 with body weight over $50 \mathrm{~kg} ; 500 \mathrm{mg}$ bid for Days 1 and 2 and $500 \mathrm{mg}$ qd for Days 3-7 for adults with body weight $<50 \mathrm{~kg}$ )

Chloroquine/hydroxychloroquine in prophylaxis for COVID-19 is not recommended. At present, there is no evidence of efficacy of this drug in the prevention of disease COVID-19.

Chloroquine $500 \mathrm{mg}$ twice daily for 20 days OR hydroxychloroquine $200 \mathrm{mg}$ BID in patients with COVID-19 irrespective of the severity of symptoms

Results of ongoing clinical trials of

chloroquine/hydroxychloroquine efficacy in the treatment of SARS-CoV2 should be awaited before definite recommendations are provided for or against the use of these drugs

No recommendation

No recommendation

No re

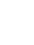

$500 \mathrm{mg}$ of twice a day in patients with mild, moderate, and severe forms of COVID-19 pneumonia [2].

With huge experience over the past 5 years in patients with long-term treatment ( $>1$ year), for different indications, Lagier et al. recommended dosage for hydroxychloroquine of $600 \mathrm{mg} /$ day with which concentration of $1 \mu \mathrm{g} / \mathrm{mL}$ is reached [13]. They also suggest administration of loading dose, followed by a maintenance dose and express their opinion that activity of hydroxychloroquine on viruses is probably the same as that of chloroquine, giving preference to hydroxychloroquine [13].

As a specific treatment for COVID-19 disease, Yao et al. recommended that the optimal dosing regimen for hydroxychloroquine should be a loading dose of $400 \mathrm{mg}$ twice daily for 1 day followed by $200 \mathrm{mg}$ twice daily [3]. However, similarly, as for Whipple disease, some authors make alternative recommendations of $600 \mathrm{mg}$ total daily dose [14].

\section{Effects on QT interval and recommendations}

Chloroquine and hydroxychloroquine are listed as drugs that have known risk of polymorphic ventricular arrhythmia "Torsades de Pointes" (TdP), due to QT interval prolongation at crediblemeds.org. They have proarrhythmogenic effect through blocking $\mathrm{I}_{\mathrm{Kr}}$ (rapid delayed rectifier potassium current) channels, causing a significant reduction in the amplitude of potassium tail currents [15] (Figure 1).

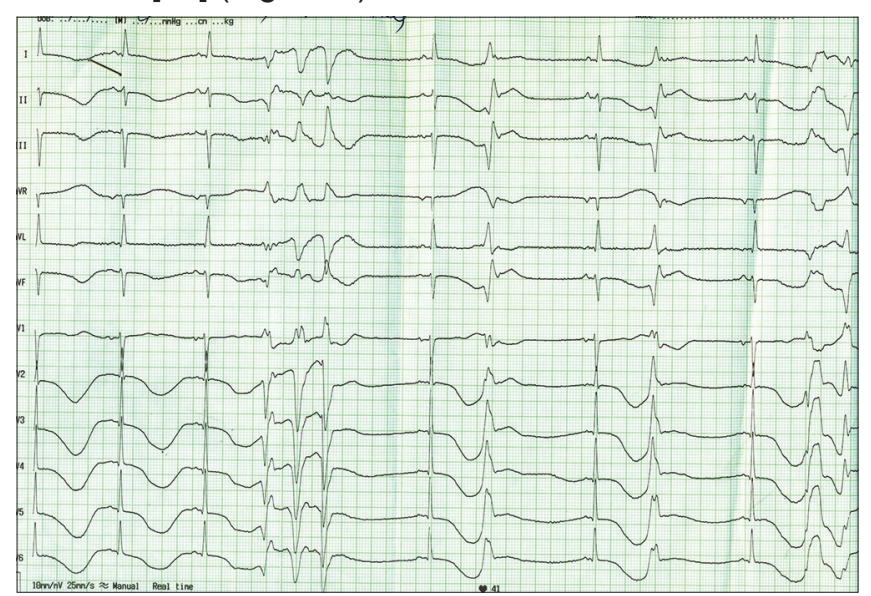

Figure 1: Hydroxychloroquine effect on electrocardiogram

The preliminary findings from the CloroCovid-19 trial suggest that a higher dosage of chloroquine should not be recommended for the treatment of severe COVID19 , especially in combination with azithromycin and/or oseltamivir, because of safety concerns [10]. Increased mortality was observed due to QTc interval prolongation and associated proarrhythmias [10] (Figure 1).

The most used formula for QTc interval calculation is the Bazett formula:

$$
\mathrm{QTC}=\mathrm{QT} / \sqrt[2]{\mathrm{RR}}
$$

European Society of Cardiology has recently released "Guidance for the Diagnosis and Management 
of CV disease during the COVID-19 pandemic" last updated on April 21, 2020 [16]. Before administration of chloroquine or hydroxychloroquine therapy, there are some suggestions:

- Drug-drug interactions including antiviral, antiarrhythmic, and anticoagulation drugs should be considered;

In hemodynamically stable patients with atrial fibrillation or flutter, discontinuation of antiarrhythmic drugs and initiation of rate control therapy to allow safe use of hydroxychloroquine as antiviral medication is a reasonable therapeutic option.

When chloroquine or hydroxychloroquine therapy is started, the following interventions should be considered in order to reduce the risk of malignant arrhythmia and death [16], [17]:

- Withholding the drugs in patients with baseline QT prolongation (especially QTc $\geq 500 \mathrm{~ms}$ ) or with known congenital long QT syndrome.

- On-treatment ECGs are recommended to monitor cardiac rhythm and rule out a significant prolongation of QTc (>500 ms, or by $>60$ ms vs. baseline)

- $\quad$ It is worth exploring alternative ECG monitoring methods (e.g., monitoring leads, smartphoneenabled mobile ECG, and handheld devices); Correction of hypokalemia to levels of $>4 \mathrm{mEq} / \mathrm{L}$ targeting $>4.5 \mathrm{mEq} / \mathrm{L}$ and hypomagnesemia to levels of $>2 \mathrm{mg} / \mathrm{dL}$.

The safety of QT-prolonging medications may be maximized by close monitoring and optimization of these factors. A risk score has been derived and validated by Tisdale et al., for the prediction of drug-associated QT prolongation among cardiac-care-unit-hospitalized patients [18]. Factors incorporated in this score are: Female gender, age $\geq 68$ years, concomitant use of loop diuretics, antiarrhythmic drugs, and comorbidities such as acute myocardial infarction, heart failure, sepsis, hypokalemia, and admission QTc $\geq 450 \mathrm{~ms}$. According to present additional factors, Tisdale score predicts low, medium, or high risk of drug-associated QT prolongation. The goal of QTc screening in this setting is not to identify patients whom are not candidates for therapy but to identify those who are at increased risk for TdP so aggressive countermeasures may be implemented [19].

\section{Conclusion}

There is a lack of evidence regarding the efficacy and risk of different treatment strategies in patients with COVID-19 disease. In this circumstance, facing deadly disease, many hospitals have simply been giving hydroxychloroquine to patients, reasoning that it might help and probably will not hurt because it is relatively safe.

To stay on a safe side, before we get relevant results from ongoing clinical studies in all patients undergoing antiviral treatment, including chloroquine or hydroxychloroquine, it is necessary to correct modifiable predisposing factors to QTc prolongation: Electrolyte imbalances, concomitant unnecessary drugs, and bradycardia.

Not to forget, while the patient is on chloroquine or hydroxychloroquine treatment ECG should be monitored also for conduction disturbances, despite these are rare and referred only during long-term treatment.

Definite recommendations will emerge once the results of ongoing clinical trials of chloroquine/ hydroxychloroquine efficacy in the treatment of SARS-CoV2 will be published.

Until than cautiously use is wise, with an awareness of side effects.

\section{References}

1. Wang M, Cao R, Zhang L, Yang X, Liu J, Xu M, et al. Remdesivir and chloroquine effectively inhibit the recently emerged novel coronavirus (2019-nCoV) in vitro. Cell Res. 2020;30(3):269-71. https://doi.org/10.1038/s41422-020-0282-0 PMid:32020029

2. Gao J, Tian Z, Yang X. Breakthrough: Chloroquine phosphate has shown apparent efficacy in treatment of COVID-19 associated pneumonia in clinical studies. Biosci Trends. 2020;14(1):72-3. https://doi.org/10.5582/bst.2020.01047 PMid:32074550

3. Yao $\mathrm{X}$, Ye F, Zhang $\mathrm{M}$, et al. In vitro antiviral activity and projection of optimized dosing design of hydroxychloroquine for the treatment of severe acute respiratory syndrome coronavirus 2 (SARS-CoV-2). Clin Infect Dis. 2020;9:ciaa237. https://doi. org/10.1093/cid/ciaa237

PMid:32150618

4. Food and Drug Administration. Fact Sheet for Health Care Providers: Emergency Use Authorization (EUA) of Hydroxychloroquine Sulfate Supplied from the Strategic National Stockpile for Treatment of COVID-19 in Certain Hospitalized Patients; 2020. Available from: https://www.fda. gov/media/136537/download. [Last accessed on 2020 May 01].

5. Al-Bari AA. Targeting endosomal acidification by chloroquine analogs as a promising strategy for the treatment of emerging viral diseases. Pharm Res Per. 2017;5(1):e00293. https://doi. org/10.1002/prp2.293

PMid:28596841

6. Al-Bari MA. Chloroquine analogues in drug discovery: New directions of uses, mechanisms of actions and toxic manifestations from malaria to multifarious diseases. J Antimicrob Chemother. 2015;70(6):1608-21. https://doi. org/10.1093/jac/dkv018

PMid:25693996

7. Savarino A, Boelaert JR, Cassone A. Effects of chloroquine on viral infections: An old drug against today's diseases? 
Lancet Infect Dis. 2003;3(11):722-7. https://doi.org/10.1016/ s1473-3099(03)00806-5

\section{PMid:14592603}

8. Gautret P, Lagier JC, Parola P, Hoang V, Meddeb L, Mailhe M, et al. Hydroxychloroquine and azithromycin as a treatment of COVID-19: Results of an open-label non-randomized clinical trial. Int J Antimicrob Agents. 2020;20:105949. https://doi. org/10.1101/2020.03.22.20040949

\section{PMid:32205204}

9. Chen J, Liu D, Liu L, Liu P, Xu Q, Xia L, et al. A pilot study of hydroxychloroquine in treatment of patients with common coronavirus disease-19 (COVID-19). Zhejiang Da Xue Xue Bao Yi Xue Ban. 2020;49(2):215-9.

PMid:32391667

10. Borba MG, Val FF, Sampaio VS, Alexandre MA, Melo GC, Brito $\mathrm{M}$, et al. Cloro covid-19 team. Effect of high vs low doses of chloroquine diphosphate as adjunctive therapy for patients hospitalized with severe acute respiratory syndrome coronavirus 2 (SARS-CoV-2) infection: A randomized clinical trial. JAMA Netw Open. 2020;3(4):e208857. https://doi. org/10.1001/jamanetworkopen.2020.8857

PMid:32339248

11. Barbosa J, Kaitis D, Freedman R. Clinical outcomes of hydroxychloroquine in hospitalized patients with COVID19: A quasi-randomized comparative study. N Engl J Med 2020;1:8882.

12. Chen Z, Hu J, Zhang Z. Efficacy of Hydroxychloroquine in Patients with COVID-19: Results of a Randomized Clinical Trial. ChiCTR2000029559; 2020.

13. Lagier JC, Fenollar F, Lepidi H, Lepidi H, Giorgi R, Million M, et al. Treatment of classic Whipple's disease: From in vitro results to clinical outcome. J Antimicrob Chemother 2014;69(1):219-27. PMid:23946319

14. Colson P, Rolain JM, Lagier JC, Brouqui P, Raoult D. Chloroquine and hydroxychloroquine as available weapons to fight COVID19. Int J Antimicrob Agents 2020;55(4):105932. https://doi. org/10.1016/j.ijantimicag.2020.105932

PMid:32145363

15. Capel RA, Herring N, Kalla M, Yavari A, Mirams GR, Douglas $G$, et al. Hydroxychloroquine reduces heart rate by modulating the hyperpolarization-activated current If: Novel electrophysiological insights and therapeutic potential. Heart Rhythm. 2015;12(10):2186-94. https://doi.org/10.1016/j. hrthm.2015.05.027

PMid:26025323

16. Guidance for the Diagnosis and Management of CV Disease during the COVID-19 Pandemic COVID-19-and-Cardiology/ESCCOVID-19-Guidance; 2020. https://doi.org/10.1002/bjs.11646

17. Roden DM, Harrington RA, Poppas A, Russo AM. Drug interactions on QTC in exploratory COVID-19 treatment. Circulation 2020;2020:1161. https://doi.org/10.1161/ circulationaha.120.047521

PMid:32267732

18. Tisdale JE, Jayes HA, Kingery JR, Mourad NA, Trujillo TN, Overholser BR, et al. Development and validation of a risk score to predict QT interval prolongation in hospitalized patients. Circ Cardiovasc Qual Outcomes. 2013;6(4):479-87. https://doi. org/10.1161/circoutcomes.113.000152 PMid:23716032

19. Simpson TF, Kovacs RJ, Stecker EC. Ventricular Arrhythmia Risk Due to Hydroxychloroquine-azithromycin Treatment for COVID-19. Cardiology Magazine; 2020. 